\title{
DINÁMICA DE CASA Y PODER LOCAL EN LA CIUDAD DE OURENSE: DON JUAN NICOLÁS DE ESPINOSA FEIJÓO, I MARQUÉS DE BÓVEDA DE LIMIA (1657-1743)
}

\author{
Antonio Presedo Garazo \\ Universidade de Vigo
}

\begin{abstract}
RESUMEN. En el siguiente trabajo se estudia la familia Espinosa como familia de poder vinculada al concejo de la ciudad de Ourense durante la edad moderna, poniendo especial énfasis en la etapa de transición entre los siglos XVII y XVIII. En un primer apartado analizamos la trayectoria familiar en la larga duración, para localizar y examinar los condicionantes que influyen en su reproducción social. El segundo se centra específicamente en el examen detallado de la relación que mantienen los Espinosa con el concejo orensano, atendiendo a los oficios servidos y el contexto en el cual se produce su traspaso entre los miembros de esta familia de poder. En el tercer y último apartado se destaca la contribución de los familiares que han accedido al alto clero secular y al ejército, como dos importantes vías de promoción social.
\end{abstract}

Palabras clave: familia de poder, concejo de Ourense, regidor, oligarquía urbana, trayectoria familiar.

ABSTRaCT. In this work, we study the Espinosa family as a powerful family that was closely bound to the Ourense's town council during the Early Modern Age, paying special attention to the transitional stage from the Seventeenth to the Eighteenth centuries. In the first chapter, family evolution is analysed in the longue durée to localize and examine the determining factors of its social reproduction. The second chapter is focussed on the analysis of the relationship between the Espinosas and the Ourense's town council, considering the family offices and the political context in which they are transferred by the members of this powerful family. In the third chapter, we also examine cathedral clergy and army as two important ways of social promotion for this family.

Keywords: powerful family, Ourense's town council, alderman, urban oligarchy, family evolution.

Recibido: 29-1-2020 - Aceptado: 4-3-2020 • antonio.presedo@uvigo.es 
En 1696, Nuño de Espinosa Sotelo incluyó en una cláusula de su testamento que otorga ese mismo año, con la cual pretende beneficiar a su hijo Juan Nicolás de Espinosa Feijóo con un nuevo vínculo, una justificación muy reveladora de la antigüedad y destacada trayectoria de su familia en la ciudad de Ourense:

por quanto de más de duçienttos y çinqüenta años a esta parte dio prinçipio a la familia de Espinosa el señor Rui Garçía de Espinosa, de quien prozedo, y [...] siempre se manttubo dicha familia con todo lustre ocupando y ejerciendo los oficios más condecorados de la república, como son los de rexidores, corregidor, jueses y ottros ${ }^{1}$.

Advertirá el lector que, tras estas palabras, intencionadamente seleccionadas para el documento que recoge sus últimas voluntades, subyacen dos ideas que este pretende transmitir a los posibles receptores. La primera es que, a finales del siglo XVII, coincidiendo con el epílogo del reinado de Carlos II, Nuño no duda en manifestar su pertenencia a una familia muy concreta - la de los Espinosa orensanos - que puede presumir del valor simbólico que aporta la antigüedad de sus orígenes. Apenas dos años antes, en sendos expedientes que se llevan a cabo para que precisamente su hijo Juan Nicolás y su otro vástago Martín Carlos puedan acceder a un hábito de la orden militar de Santiago, ya había sido recogida una cantidad considerable de testimonios y pruebas que evidenciaban esto mismo ${ }^{2}$. Así que Nuño no hace sino subrayar la singularidad de su familia en dicho sentido, ya suficientemente reconocible por la sociedad auriense de entonces (Atienza Hernández, 1997; Fortea Pérez, 2005, pp. 251-254). La segunda es que, además, aquella se había distinguido desde esos remotos orígenes por el ejercicio de una serie de oficios públicos, que él mismo no duda en identificar, dejando entrever que se trata de los «más condecorados» y que su dilatada trayectoria no se puede desligar de esa circunstancia. En resumidas cuentas, está queriendo dejar bien claro que pertenece a lo que los historiadores denominamos una familia de poder.

Dedicaremos las páginas que siguen a comprobar hasta qué punto sus palabras tuvieron fiel reflejo en el comportamiento de quienes integran las sucesivas generaciones de la suya en particular. O expresado en otros términos, estudiaremos a los Espinosa como una familia de poder, sin perder de vista — ya anunciamos — las pervivencias y los cambios que se aprecian en dicho campo de observación acotado al pasar del siglo XVII al XVIII. Para ello, seguiremos una metodología análoga a la ya empleada en otras investigaciones sobre familias de poder durante la edad moderna, en la que se combina

Archivo Histórico Provincial de Ourense (en adelante AHPOu), Protocolos Notariales (en adelante PN), Ourense (en adelante Ou), c. 3422/01 (1696), f. 213 r/v.

2 Archivo Histórico Nacional (en adelante AHN), Órdenes Militares (en adelante OOMM), Santiago, exps. 2765 y 2766 . 
el estudio de la trayectoria familiar con el de la relación que estas mantienen con aquellas instituciones que facilitan el acceso al poder (Rodríguez Sánchez, 1992; Hernández Benítez, 1995, pp. 234-271; Hernández Franco, 1998; Dedieu y Windler, 1998; Pérez Ortiz, 2002; Angulo Morales, 2007; Casey, 2007; Jiménez Martínez de Lagrán, 2009; Chaparro Sainz, 2012; y Precioso Izquierdo, 2017, entre otros); si bien, teniendo en cuenta una serie de consideraciones específicas que atañen a nuestro caso concreto.

La primera de ellas se halla condicionada por la evolución que experimenta la principal institución con la que estos se relacionan a lo largo de dicha época histórica: el concejo de esta ciudad, a la cual corresponde la capitalidad provincial. En este sentido, las investigaciones de María López Díaz representan el referente historiográfico a tener en cuenta, interesándonos muy especialmente su análisis del acrecentamiento municipal — con sus causas y consecuencias-, toda vez que este da lugar a desórdenes en el funcionamiento de la institución que repuntan justo cuando Nuño redacta su testamento; como también el de las dinámicas diferenciadas que se aprecian entre las familias que configuran la oligarquía urbana, a la hora de examinar la relación que estas mantienen con el consistorio (López Díaz, 2011a, pp. 155-197 y 257-294; ID., 2013a, pp. 110-116; ID., 2013b).

De hecho, en segundo lugar, nuestra investigación ha sido planteada como una nueva contribución a la línea de trabajo propuesta desde el modernismo orensano sobre familias de poder (López Díaz, 2011b), que ya cuenta en su haber con estudios monográficos sobre los Méndez Montoto, los Boán y los Vivero (Peláez Rivero, 2010; Rionegro Fariña, 2013; Presedo Garazo, 2016); y que permite llevar a cabo una relectura de otros trabajos que, partiendo de un enfoque no académico y más erudito, aportan información igualmente relevante sobre otros casos, como puedan serlo los mencionados Boán, los Salgado Gundín, los Lemos o los propios Espinosa (Ferro Couselo, 1972; Gómez Buxán, 2007; Bangueses Cobelas, 2012; Gallego Domínguez, 2005). Concretamente, este último ha sido objeto de una exhaustiva revisión por nuestra parte, como no podía ser de otro modo si se pretendía emplear con rigor la metodología que se aplica al estudio de las familias de poder en los términos señalados.

En tercer lugar, para cumplir con nuestro objetivo, nos hemos decantado por un guión común a este tipo de investigaciones que nos ha permitido articular nuestra reflexión en torno a dos pilares fundamentales: $1^{\circ}$ ) la trayectoria de la familia seleccionada atendiendo a los ejes vertebrales de su dinámica de reproducción social en la larga duración; y $2^{\circ}$ ) la relación que esta mantiene con las instituciones locales, entre las cuales destaca por su peso específico el concejo orensano. Como se podrá comprobar, le corresponde a Juan Nicolás de Espinosa Feijóo — quien sucede a su padre en la jefatura de la casa a finales de 1696 - el rol de figura clave en el tránsito entre ambas centurias, señalando un antes y un después en la trayectoria familiar durante 
las primeras décadas del siglo XVIII, de ahí que hayamos elegido su cronología vital como marco de referencia para nuestro trabajo ${ }^{3}$.

\section{Trayectoria secular de la familia Espinosa}

Fijar la genealogía de los Espinosa orensanos previamente a la generación de la cual forma parte García de Espinosa — abuelo de Nuño de Espinosa Sotelo-, en la segunda mitad del siglo XVI, a quien se debe la fundación del mayorazgo en 1603, es una tarea que todavía se nos antoja harto difícil de acometer ${ }^{4}$. La no conservación de un archivo familiar privado y la escasez de registros parroquiales anteriores a 1572 en santa Eufemia la Real de Ourense, de la cual eran feligreses, explican en parte esta limitación, apenas subsanable con documentación de diversa índole que permite identificar a ciertos personajes que portan este apellido y residen en esta ciudad desde finales del XIV ${ }^{5}$. Entre estos, debemos destacar a García Díaz de Espinosa, escudero del obispo y regidor en el concejo urbano, como figura relevante durante la última década de dicha centuria y las cuatro primeras del xv; y a Roi García de Espinosa, asentado como alcalde en el padrón de la Santa Hermandad realizado en 1498 (Ferro Couselo, 1967[I,] pp. 123-128 y 1967[II], pp. 389-392, 402-403; López Carreira, 1993, pp. 26-27, 35; ID., 1995, p. 282). Pero las limitaciones heurísticas nos impiden plantear aún cualquier hipótesis plausible acerca de la existencia de un probable parentesco entre ambos personajes tardomedievales, y menos aún entre cualquiera de estos por separado con otros coetáneos suyos o, ya más tardíamente, en 1540-1575, con María Fernández de Espinosa — casada con el capitán Pedro Yáñez de Nóvoa-y, en 1584, con Alonso de Nóvoa de Espinosa — sobrino de la anterior, regidor y casado con doña María Sotelo- (Gallego Domínguez, 2005, pp. 56-57). Queda fuera de toda duda, eso sí, que ya habían echado raíces aquí en el último siglo medieval y que, desde entonces, al igual que los Nóvoa, otra familia homóloga coetánea, venían ocupando los niveles más elevados de la sociedad orensana y, directamente relacionado con ello, puestos relevantes y de prestigio en las instituciones locales (Gallego Domínguez y Fariña Busto, 2005). De hecho, en el siglo que trascurre entre 1419 y 1522, nos los

3 El cuadro cuadro genealógico de la familia Espinosa, marqueses de Bóveda de Limia, que se adjunta ayudará al lector a situar a cada miembro de esta familia de poder orensana en la generación correspondiente.

$4 \quad$ Archivo Histórico Diocesano de Ourense (en adelante AHDOu), PN, c. 528 (1603), ff. 4r-5v; y AHN, OOMM, Santiago, exps. 2765, ff. 47v-48r, y 2766, f. 61v.

AHDOu, Fondos parroquiales (en adelante FP), Libros de actas sacramentales (en adelante LAS), santa Eufemia la Real-Centro, libs. 30.9 .1 (1542-1591), 30.9 .2 (1592-1619), 30.9 .3 (1620-1641), 30.9.4 (1636-1663), 30.9.5 (1664-1709); santa Eufemia la Real-Norte, libs. 30.14.1 (1643-1682), 30.14.1 bis (1678-1697), 30.14.2. (1697-1720). 
encontramos en el concejo (como regidores y procuradores generales) en 1419, 1429, 1431-1439 y 1513, en el cabildo catedralicio (como canónigos, tesoreros y racioneros) en 1430-1439, 1460-1479 y 1522, y consumando enlaces matrimoniales con el sector de los letrados en 1522 (López Carreira, 1998, pp. 564, 568, 570, 611-617; Gallego Domínguez, 2005, p. 55).

Cuando se produjo el nacimiento de García de Espinosa, con toda probabilidad en el tramo central del siglo XVI, la familia había dado lugar al menos a dos líneas sucesorias que conservan, o bien han logrado recuperar, el estatus consolidado en la etapa Trastámara y años iniciales del reinado de Carlos I, y mantienen cierta relación hasta finales del Quinientos, como acredita el hecho de que apadrinen a algunos de sus respectivos vástagos ${ }^{6}$. La primera, que incluye a la citada María Fernández de Espinosa, ha emparentado con los Nóvoa y los Sotelo y cuenta con un capitular en el concejo - su sobrino Alonso - . La segunda y principal, a la cual pertenece García de Espinosa, es la que realmente nos interesa aquí. Hacia finales del XVI y primer tercio del XVII, residen en Ourense, además, otros Espinosa que desempeñan oficios artesanales como plateros y cordoneros, sin que hayan perdido el contacto con la línea principal; y otros que forman parte del sector de los letrados?.

Centrándonos en los antepasados directos de Juan Nicolás de Espinosa Feijóo, la segunda generación ascendiente al mismo también se relaciona con los hombres de leyes de la ciudad, a quienes bien podríamos aplicarles los términos empleados para identificarlos en Santiago de Compostela en esta etapa inicial de la edad moderna: una fuerza emergente (Gelabert González, 1982, pp. 289-293). No es precisamente lo poco que sabemos sobre García de Espinosa - uno de sus dos bisabuelos paternos e integrante de la tercera generación ascendiente-, lo que nos ha permitido llegar a esta conclusión, aunque sin sus esfuerzos difícilmente habrían podido incorporarse al grupo de los letrados sus tres vástagos supervivientes. De este García nos interesa destacar dos cuestiones. La primera es que uno de sus hermanos conocidos es capitular del cabildo catedralicio y, a la vez, está en condiciones de sufragar la construcción de una capilla en la catedral; lo cual nos pone sobre la pista de que esta línea familiar gozaba de una posición social y económica ya consolidada en el contexto local en la

AHDOu, FP, LAS, lib. 30.9.1, ff. 105r y 126v; lib. 30.9.2, f. 333r. En 1568, los Spinosas comparten el derecho de presentación de la feligresía de san Pedro de Leirado con otros patronos, aunque todo apunta a que en 1654 ya lo han perdido. Archivo Catedralicio de Ourense, Visitas pastorales, Libro de visitas de los beneficios de este Obispado de Orense, año de 1566 a 1568, f. 181v, y Libro 2. ${ }^{\circ}$ de Visitas y otros papeles tocantes a ellas, f. 479r.

Juan y Bartolomé de Espinosa figuran como plateros en 1595 y 1616 respectivamente, y Pedro de Espinosa cordonero en 1617 (AHDOu, FP, LAS, lib. 30.9.2, ff. 49r bis, 315v y 332r). Entre los letrados: Juan de Espinosa consta como escribano real en 1616 y 1618, otro Juan de Espinosa el moço es escribano de número de Ourense en 1621, y un tercer Juan de Espinosa - licenciado- ejerce de fiscal eclesiástico en 1622 (Ibid., lib. 30.9.2, ff. 316v y 342v; lib. 30.9.3, ff. 35v y 36v). 
segunda mitad del $\mathrm{XVI}^{8}$. Y la segunda es que a él se debe la fundación del mayorazgo en $1603^{9}$, coincidiendo, por tanto, con la primera etapa en que se concentran las fundaciones vinculares de la nobleza provincial orensana (Presedo Garazo, 2013, p. 92), pocos años antes de que los Méndez Montoto hagan lo propio en 1608 (Peláez Rivero, 2010, pp. 35-36). Ya entonces, los Espinosa habían asumido como parte de su capital simbólico que «el solar conocido de dicho apellido» se correspondía con su residencia principal en la ciudad de Ourense ${ }^{10}$.

Es en la siguiente generación, la compuesta por sus cinco hijos/as — cuatro varones y una mujer - que tuvo con María Muñiz, cuando realmente podemos asociar a esta familia con el grupo de los letrados ${ }^{11}$. Su primogénito, el licenciado Francisco de Espinosa, es abogado; su otro hijo Andrés de Espinosa es escribano real; y su hija María de Espinosa se casa con Juan de Puga, escribano de número de la ciudad ${ }^{12}$. Los tres hermanos tienen descendencia directa, si bien es con el primero de ellos con quien se consolida la línea sucesoria troncal tras ser beneficiado con el mayorazgo fundado por su padre (Clavero, 1974, pp. 211-214). Casado en tres ocasiones, el licenciado Francisco de Espinosa estaba desposado en 1603 con la primera de sus tres mujeres: María López de Garza, que aporta como bienes dotales una de las granjas que la familia posee en los alrededores de la ciudad —Ervedelo-, y con quien tiene una hija $^{13}$. Con su segunda esposa, Constanza Arias de Malburgo, se materializa el acceso de la familia al concejo, puesto que recibe de su suegro Rodrigo Arias de Malburgo, en 1609, el oficio de depositario general con voz y voto de regidor «por dos vidas» (López Díaz, 2013b, p. 191). A partir de entonces, este oficio municipal va a permanecer en manos de los Espinosa aún no habiendo tenido este descendencia con aquella, siendo incorporado al mayorazgo en $1635^{14}$. Nos detendremos con más detalle en el siguiente apartado a valorar el contexto político en el que se produce su irrupción en el consistorio auriense a comienzos del siglo XVII; si bien ahora nos interesa, $1^{\circ}$ ) fijar dicho hito en la historia familiar, y $2^{\circ}$ ) que, en adelante, pasan a formar parte de la oligarquía urbana orensana.

$8 \quad$ Se trata de la capilla de san Andrés, en cuya ubicación se construyó posteriormente la sacristía catedralicia. AHDOu, PN, c. 528 (1603), f. 4r. Para el coste de las capillas de la oligarquía urbana orensana en el deambulatorio catedralicio construido durante el primer tercio del siglo XVII, vid. Presedo Garazo, 2019, p. 112.

AHDOu, PN, c. 528 (1603), ff. 4r-5v; y AHN, OOMM, Santiago, exps. 2765, ff. 47v-48r, y 2766, f. $61 \mathrm{v}$. En dicha fundación, García encarga a todos y cada uno de los futuros usufructuarios del mayorazgo que realicen una agregación vincular. AHPOu, PN, Ou, c. 3422/01 (1696), f. 213v. Una descripción del escudo armoriado de la familia situado en la fachada de dicho pazo urbano en 1694, en AHN, OOMM, Santiago, exp. 2765, f. 49r.

11 AHDOu, FP, LAS, lib. 30.9.1, ff. 67r, 105r y 126v; y AHDOu, PN, c. 528 (1603), f. 4v.

12 AHDOu, FP, LAS, lib. 30.9.2, ff. 185r, 279r; lib. 30.9.3, ff. 39v, 181r y 238v.

13 AHDOu, FP, LAS, lib. 30.9.2, f. 90r.

14 AHPOu, PN, Ou, c. 3571/02 (1635), ff. 1r-3v. 
|)

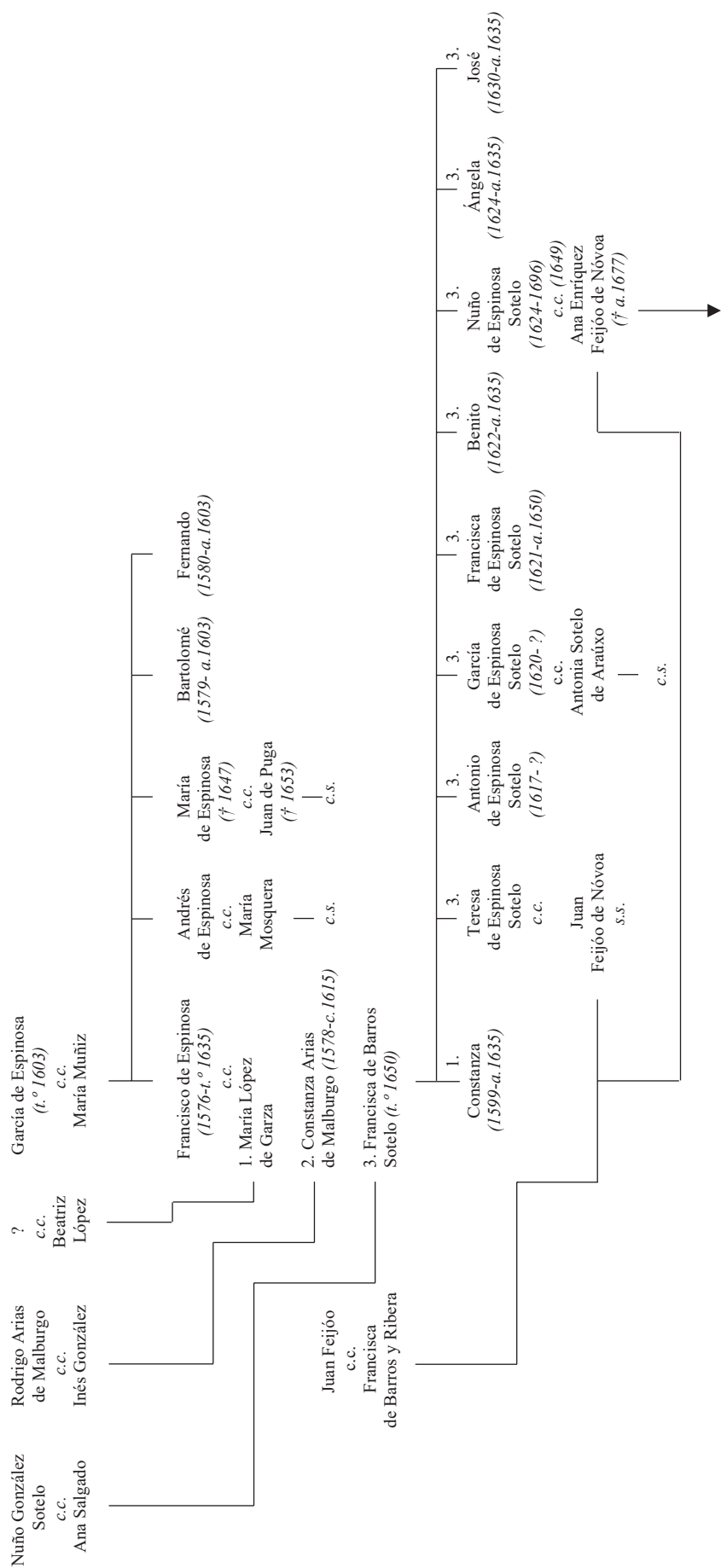




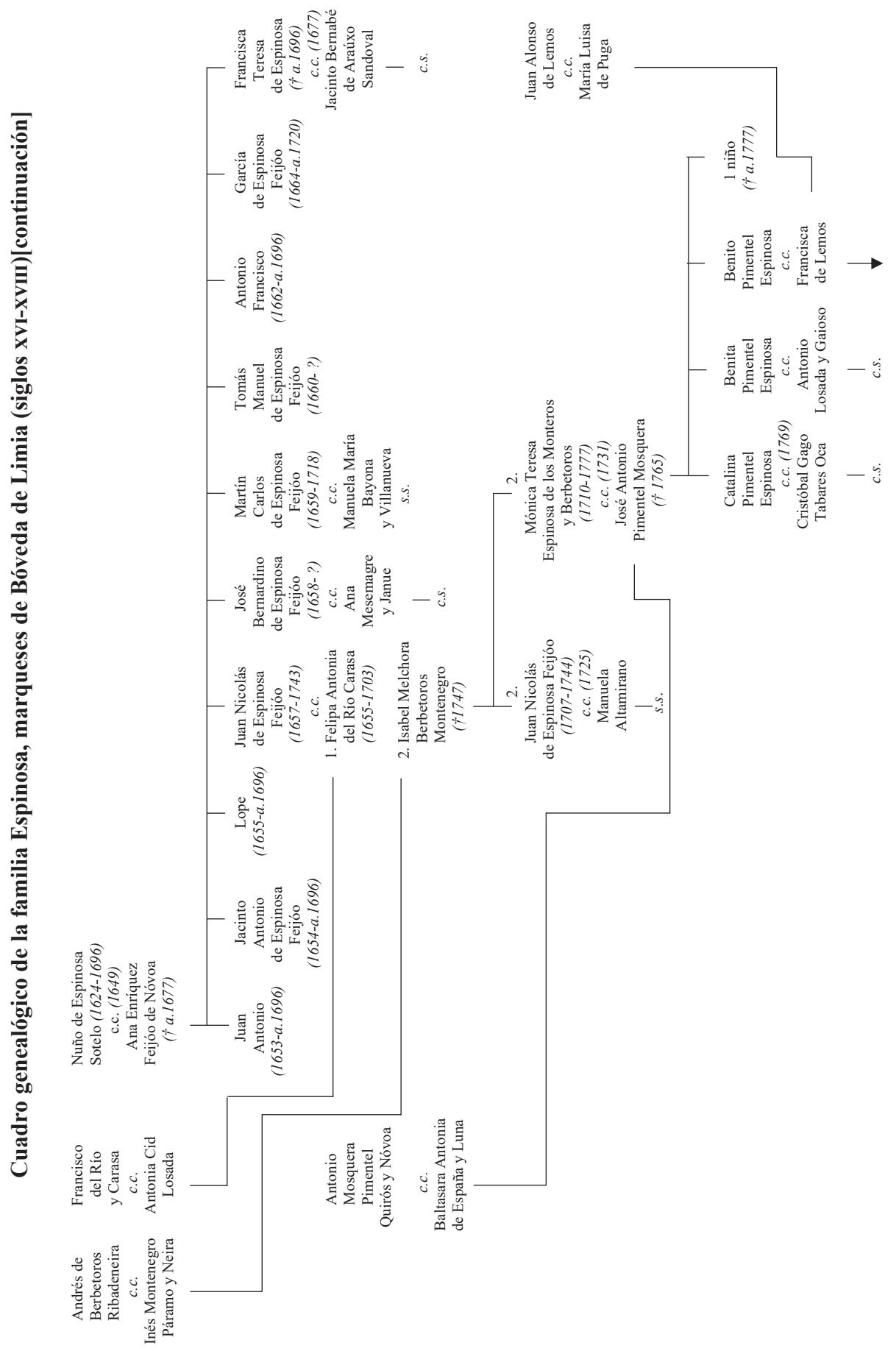


El licenciado Francisco de Espinosa casó en terceras nupcias con Francisca de Barros Sotelo, de la villa de Monterrei, con quien tiene abundante descendencia: ocho hijos/as — cinco varones y tres mujeres - nacidos entre 1618 y $1630^{15}$ (el antepenúltimo de los cuales es el citado Nuño de Espinosa Sotelo), coincidiendo su alumbramiento con los años en que ocupa el puesto político de mayor rango en la ciudad: primero como teniente de corregidor y luego como corregidor interino (Gallego Domínguez, 2005, p. 58; López Díaz, 2011a, p. 192). Amplía además el patrimonio familiar con la adquisición de inmuebles y rentas en la capital provincial y localidades rurales próximas (Bóveda, Piñor y Tamallancos entre otras), cede bienes rústicos en foro y ganado menor en aparcería, actúa como prestamista y toma en arriendo frutos parroquiales ${ }^{16}$. Asimismo, solicita ser enterrado en la capilla catedralicia fundada en 1623 por su tío el deán Antonio Sotelo y Nóvoa - hijo del regidor Alonso de Nóvoa de Espinosa - (Yzquierdo Perrín, 1995, pp. 124-125), y agrega al vínculo familiar en 1635 la granja de Ervedelo y — como ya hemos comentado — «el oficio de regidor y depositario general desta ciudad ${ }^{17}$.

Con la siguiente generación, esto es, la compuesta por los nueve vástagos del licenciado Espinosa, la familia refuerza su dinámica expansionista. La puesta en práctica de una política matrimonial restrictiva sólo permite que contraigan nupcias tres de ellos, permaneciendo célibes el resto, y facilita, a mayores, que el grueso del patrimonio familiar permanezca bajo control del nuevo jefe de casa: Nuño de Espinosa Sotelo. El casamiento a truque de este y su hermana Teresa con dos hijos habidos de la unión entre Juan Feijóo de Nóvoa — señor del coto de Bóveda de Limia — y Francisca de Barros Ribera — parienta, a su vez, de Francisca de Barros Sotelo-, sin que quede descendencia directa del capitán Juan Feijóo de Nóvoa con Teresa, facilita que este coto vaya a parar a manos de los Espinosa ${ }^{18}$. Sí queda descendencia directa, en cambio, de su hermano García con Antonia Sotelo de Araúxo, por lo que la granja de A Barxa será objeto de disputa entre Nuño y su sobrino-nieto Jacinto Bernabé de Araúxo y Espinosa ${ }^{19}$.

15 AHDOu, FP, LAS, lib. 30.9.2, f. 333r; lib. 30.9.3, ff. 16r, 21v, 38v, 63r, 138r y 231r; AHPOu, PN, Ou, c. 3571/02 (1635), ff. 1r-3v; y AHDOu, PN, c. 657 (1650), ff. 23r-26r.

16 AHPOU, PN, Ou, c. 3571/01 (1634), ff. 81r-83r, 102r-108v, 203r-205v, 252r-253v, 260r-262v, $366 \mathrm{r}-367 \mathrm{v}, 385$ r/v y 389 r/v; c. $3571 / 02$ (1635), ff. 102r-106v, 126r-127v, 140r-141v, 173-174v, 177 r/v, 185 r/v, 213 r/v, 252 r/v y 259r-260v; c. $3571 / 03$ (1636), ff. 373 r/v y 402 r/v. Su tercera mujer, Francisca de Barros Sotelo continúa con la adquisición de nuevos predios en 1639, tras haber enviudado. Ibid., c. 3572/02 (1639), ff. 264r-265v.

AHPOu, PN, Ou, c. 3571/02 (1635), ff. 1r-3v.

AHPOu, PN, Ou, c. 3422/01 (1696), f. 210v; y AHN, OOMM, Santiago, exp. 2765, ff. 68r-69v.

AHDOu, FP, LAS, lib. 30.9.4, f. 106v. Para la administración de esta granja de A Barxa por parte de García de Espinosa Sotelo, AHPOu, Casas Particulares, Marquesado de Leis, lib. 11; y para el conflicto interfamiliar que se soluciona en 1694, AHPOu, PN, Ou, c. 3175/01 (1693), f. 28 r/v y Gallego Domínguez, 2005, p. 65. 
Tanto en esta generación como en las dos siguientes, algunos de sus integrantes dedican parte de sus vidas a servir al rey con las armas, contribuyendo con ello al reforzamiento del estatus familiar. Volveremos sobre dicha cuestión en páginas siguientes, aunque debemos destacar ahora justamente a los dos hermanos Nuño y García en este sentido. El segundo — de mayor edad — será distinguido con el rango de capitán en el tercio que estuvo a cargo del capitán de caballos corazas y maestre de campo Antonio Taboada Ribadeneira — señor de Taboada-, destacado en el frente orensano en el transcurso de la guerra de restauración de Portugal (Gallego Domínguez, 2005 p. 62; Díaz-Castro Lodeiro, 2012, pp. 248-251). Nuño, por su parte, alcanza la graduación de sargento mayor en «serviçio de Su Majestad» en «uno de los reximientos de ynfantería española de dichos Estados de Flandes» ${ }^{20}$. Complementariamente, algunos segundones acceden al cabildo catedralicio de Ourense durante dos generaciones sucesivas (Irigoyen López, 2000, pp. 171 ss.). En esta que nos ocupa, se reserva la carrera eclesiástica para el hermano mayor, Antonio, que se hace con una canonjía y el arcedianato auriense ${ }^{21}$.

Ya hemos señalado en la introducción que los Espinosa deben a Nuño un nuevo vínculo fundado en 1696, que se vino a añadir al mayorazgo de 1603 y la posterior agregación vincular de 1635; como asimismo el reconocimiento del lustre que había ido adquiriendo la familia en el contexto local a lo largo de una dilatada trayectoria cuya duración se atrevía a fijar en dos siglos y medio. Es poco probable, sin embargo, que alcanzase a vislumbrar los nuevos éxitos que estaban por llegar con el inicio del siglo XVIII, concretamente en las dos primeras décadas del reinado de Felipe V.

Del mismo modo que su padre, Nuño tuvo una descendencia extensa, habida en este caso con su única esposa Ana Feijóo de Nóvoa: diez hijos/as —nueve varones y una mujer - que nacen entre 1653 y $1664^{22}$. De nuevo, la política matrimonial restrictiva sólo permite que contraigan nupcias el varón que ocupa la jefatura familiar en la siguiente generación — esto es, Juan Nicolás de Espinosa Feijóo-, dos de sus hermanos que optan por el oficio de armas y su única hermana. Juan Nicolás lo hace en dos ocasiones, primero con Felipa del Río Caraza ${ }^{23}$, cuyo abuelo, Juan del Río — natural de la diócesis de Burgos-, había adquirido en 1638 un regimiento acrecentado por el rey en el concejo orensano y que recibe en herencia su padre en 1640 (López Díaz, 2011a, pp. 173, 193-196)24. El no haber tenido descendencia de su primer matrimo-

\footnotetext{
AHPOu, PN, Ou, c. 3422/01 (1696), f. 211v; y c. 3236/04 (1720-1727), f. 5r.

AHPOu, PN, Ou, c. 3572/02 (1639), ff. 286v-287v; y AHDOu, PN, c. 657 (1650) f. 24v.

AHDOu, FP, LAS, lib. 30.9.4, f. 59v, y 30.14.1, ff. 31v, 36r, 37r, 39r, 44v, 48r, 53v, 60r y 125v; y AHPOu, PN, Ou, c. 3422/01 (1696), f. 214 r/v.

23 Nacida en 1655. AHDOu, FP, LAS, lib. 30.9.4, ff. 64v-65r.

24 Al regidor y alcalde mayor de ronda Juan del Río y su mujer Felipa de Caraza Agustina se debe la fundación, en 1639, de la Ermita de Quintela en santa Marta de Velle (AHPOu, PN, Ou, c. 3573/01 (1640), ff. 155r-163v). Una hija de estos, Catalina del Río Caraza, ingresa en 1648 en el convento de san Paio de Antealtares, en Santiago de Compostela, Archivo del convento de san Paio de Antealtares, Informaciones $1, \mathrm{~A}-2, \mathrm{n} .{ }^{\circ} 20$.
} 
nio, y ser nombrado como «único y universal heredero» de Felipa, es el motivo que subyace en la sonada disputa que este va a mantener a comienzos del siglo XVIII con Jacinto de Laiseca Alvarado, vecino de la villa de Chinchón, cuya causa llega hasta el Consejo Real ${ }^{25}$. Su segundo matrimonio se concierta con Isabel Melchora Berbetoros Montenegro, procedente de los niveles elevados de la fidalguía luguesa - Casa de san Pedro de Portomarín — según se deduce de la dote que aportan sus padres - 10.000 ducados-, y con quien asegura la sucesión familiar ${ }^{26}$. Por su parte, su hermano el capitán José Bernardino, quien en 1696 se halla «sirbiendo a Su Majestad con una compañía de infanttería española en los Estados de Flandes», se casa con la flamenca Ana Mesemaqre, vecina de la ciudad de Gante; su otro hermano Martín Carlos, distinguido con la graduación de coronel en 1696 y «mariscal de campo y primer theniente de las reales guardas de alabarderos» en 1718 — poco antes de su defunción—, se desposa con la madrileña Manuela María Bayona y Villanueva; y su única hermana Francisca Teresa —-fallecida antes de 1696 - contrae nupcias con Jacinto Bernabé de Araúxo Sandoval en $1677^{27}$. Salvo Martín Carlos, los otros tres hermanos tienen descendencia directa de sus respectivos matrimonios, recayendo el mayorazgo en la de Juan Nicolás, quien se ve obligado a pleitear con Ignacio Osorio por la herencia procedente de aquel, llegando esta causa, una vez más, hasta el Consejo Real ${ }^{28}$.

Con la generación de la cual forma parte Juan Nicolás de Espinosa Feijóo culmina la dinámica expansionista de los Espinosa en el contexto local. Tanto él, como su hermano Martín Carlos, consiguen ser ordenados caballeros de hábito de la orden militar de Santiago en $1694^{29}$, un atributo de prestigio al que solían recurrir las oligarquías urbanas castellanas que no siempre estuvo al alcance de todos los munícipes orensanos (Hernández Benítez, 1995, pp. 224-228; Aranda Pérez, 1999, pp. 308-320) 30. A mediados de 1701, recién iniciado el reinado de Felipe V, el primer monarca Borbón le expide el título nobiliario de marqués de Bóveda de Limia, que le había sido concedido a finales de agosto de 1700, tres meses antes de la muerte de Carlos II (Acuña Rubio, 2002, p. 39; Felices de la Fuente, 2012, pp. 124-125). Además, Juan Nicolás

AHPOU, PN, Ou, c. 3236/01 (1719), ff. 3 r/v y 14r-15v; y c. 3236/04 (1723) ff. 112 r/v y 118 r/v. AHPOu, PN, Ou, c. 3236/04 (1720-1727), f. 7v.

AHDOu, FP, LAS, lib. 30.14 .1 bis, f. 118v; y AHPOu, PN, Ou, c. 3422/01 (1696), f. 214 r/v; c. 3236/01 (1718), f. 16 r/v; y c. 3236/04 (1720-1727), f. 9 r-12r.

$28 \quad$ Ignacio Osorio está casado con una hija que ha quedado del primer matrimonio de Manuela María de Bayona y Villanueva. AHPOu, PN, Ou, c. 3236/01 (1710-1719), ff. 5 r/v y 7r-8v de 1719; y c. 3236/04 (1720-1727), ff. 21r-22v.

30 Otra familia vinculada al concejo auriense que cuenta entre sus filas con caballeros de la Orden de Santiago son los Vivero de Lagariños (Presedo Garazo, 2016, p. 232). Para ampliar información sobre la concesión de hábitos de órdenes militares y los honores asociados a los cruzados en el siglo XVII, vid. Postigo Castellanos, 1988, pp. 111 ss. 
realiza una nueva agregación vincular en $1720^{31}$ y dirige parte de sus esfuerzos a la conservación y protección del patrimonio familiar, ora fijando nuevas rentas ${ }^{32}$, ora asegurando ante las instancias judiciales aquellos derechos de propiedad que fueron cuestionados durante el primer cuarto del siglo XVIII ${ }^{33}$.

No añadiremos más, por ahora, a lo ya expuesto sobre sus hermanos que optan por el oficio de armas, aplicando a esta generación la argumentación que hemos empleado líneas arriba al hilo de la precedente. Pero no podemos avanzar hasta la siguiente, sin antes señalar que otros dos de esta misma logran hacerse con sendas canonjías en el cabildo catedralicio auriense: García y Tomás Manuel, el segundo de los cuales incluso ocupará el puesto de tesorero en la mesa capitular ${ }^{34}$.

A diferencia de su padre, su abuelo paterno y su bisabuelo paterno Espinosa, la prole de Juan Nicolás de Espinosa Feijóo, habida de su segunda esposa, está compuesta por un solo varón y una sola mujer ${ }^{35}$. El primero de ambos, Juan Nicolás de Espinosa Feijóo y Berbetoros, contrae nupcias en 1725 con Manuela Gertrudis Arroxo Altamirano, procedente de la casa hidalga orensana de Vilar de Covelas - siendo objeto de disputa en 1737 el pago de la dote ofrecida a esta ${ }^{36}$ - y fallece en 1744, un año después de que lo haga su padre, sin que quede descendencia de esta unión. Por dicho motivo, los derechos sucesorios recaen en su hermana Mónica Teresa, a quien su padre señala su legítima en su codicilo testamentario de $1723^{37}$, pocos años antes de que contraiga matrimonio en 1731 con Juan Antonio Pimentel Mosquera, procedente de la casa hidalga coruñesa de Gallegos, cuyos dueños ya habían emparentado anteriormente con los propietarios de la orensana casa-torre de Armariz ${ }^{38}$.

De esta última unión nacen cuatro hijos/as — dos varones y dos mujeres —, nietos, por tanto, del I marqués de Bóveda de Limia, que vivían cuando se llevaron a cabo

AHPOu, PN, Ou, c. 3236/04 (1720-1727), ff. 8v-10v.

AHPOu, PN, Ou, c. 3176/02 (1698), ff. 313r-314r; c. 3177/01 (1700), ff. 116r-117v; c. 3178/06 (1706), ff. 58r-59v; c. 3236/01 (1710-1719), ff. 12r-13v de 1719; y c. 3236/04 (1720-1727), f. 78 r/v.

Archivo del Reino de Galicia (en adelante ARG), Real Audiencia (en adelante RA), Causas Particulares (en adelante CP), leg. 20.706/3 para la querella puesta en 1699 contra unos sujetos por usurpación indebida de una finca; AHPOu, PN, Ou, c. 3235/03 (1701-1704), ff. 4r-5r de 1704 para un pleito contra el monasterio de Xunqueira de Espadañado sobre dos predios; Ibid., c. 3236/01 (1710-1719), f. 13 r/v de 1716 para otra querella contra tres colonos por impago de rentas, y ff. $23 \mathrm{r}$ 24r de 1718 para la petición presentada en su contra por los monasterios de San Clodio y Oseira sobre los apeos que este realizó en la Encomienda de Batundeira; y c.3083/03 (1720-1729), ff. 13 r/v de 1723 para el litigio con el capitular orensano Francisco Benito Salgado sobre el arriendo de los frutos de la Encomienda de A Barra.

AHPOu, PN, Ou, c. 3236/04 (1720-1727), ff. 2 r/v y 11r-12r.

Ibid., f. 8 r.

ARG, RA, CP, legs. 14.471/5 (donde se incluye la dote ofrecida en 1725) y 18.432/24.

AHPOu, PN, Ou, c. 3236/04 (1720-1727), ff. 121r-122r.

AHN, Universidades, 667, exp. 125. 
en la ciudad las operaciones derivadas del catastro de Ensenada, y que conforman la sexta y última generación de los Espinosa que nos interesa ${ }^{39}$. Las dos mujeres y el varón elegido para ocupar la jefatura de la casa en la siguiente generación - Benito Mosquera Pimentel Espinosa y Berbetoros - contraen matrimonio (Gallego Domínguez, 2005 pp. 70, 73; Bangueses Cobelas, 2012, pp. 120). Así que Benito representa, pues, el último eslabón de nuestro particular campo de observación. Ingresó con 16 años, en 1754, en el Real Seminario de Nobles de Madrid, cuya fundación en 1725 había sido apoyada por Felipe V (Aguilar Piñal, 1980, pp. 330-332), con la intención de contribuir a que la nobleza española dispusiese de una institución en la que, según las constituciones fundacionales de 1730 , se pudiese educar «aquella nobleza que regularmente no sigue las universidades, y ordinariamente se emplea en el servicio de su Palacio y Corte, de sus ejércitos de mar y tierra, en el gobierno económico y político, en el manejo de los negocios de Estado; y de aquellos que, permaneciendo en sus ciudades, gobernando sus casas y crecientes mayorazgos, deben ser por su nacimiento Padres de sus Patrias» (Soubeyroux, 1995, p. 202). Aunque no sabemos el número de cursos que pasó en esta elitista institución educativa, en la que de media cursaban estudios anualmente 15 alumnos procedentes sobre todo de la pequeña nobleza provincial; este hecho no sólo pone de relieve la situación acomodada de la familia — habida cuenta del precio de alojamiento que debían abonar-, sino también que esta aspiraba a continuar reforzando su estatus con los cauces que la nueva dinastía real había puesto a disposición de sus fieles servidores ${ }^{40}$. Su matrimonio es concertado con Francisca de Lemos y Puga, quien procede de otra familia de la oligarquía urbana auriense: los Lemos del Pazo de Piñor, cuyo padre — Juan Alonso de Lemos Sarmiento de Soutomaior — había sucedido a su abuelo paterno en 1718 en una regiduría orensana provista por el rey, adquirida por su tatarabuelo en 1635, y había sido distinguido como comandante del tercio de Ourense, y cuya madre - María Luisa de Puga y Solís - era nieta por línea materna del I conde de Torre Penela (López Díaz, 2011a, p. 195; ID., 2013b, p. 215; Bangueses Cobelas, 2012, pp. 118-120). No entraremos a valorar la descendencia de ambos por no desviarnos del marco cronológico de nuestra investigación, y no extendernos más en este apartado. Pero no podemos finalizarlo sin indicar que tanto Benito Mosquera Pimentel Espinosa y Berbetoros como los siguientes jefes de casa, ya no fijarán su residencia principal en la ciudad de Ourense, de la cual incluso se van a desarraigar, poniendo fin con ello a la trayectoria secular — vinculada al ejercicio del poder en el contexto local— que había resaltado Nuño de Espinosa Sotelo en 1696 (Gallego Domínguez, 2005 pp. 73-79).

39 AHPOu, Catastro de Ensenada (en adelante CE), lib. 2565, Personal de legos de la ciudad de Ourense, f. 35bis $r$.

40 La información genealógica que debió presentar como aspirante para entrar en dicho Real Seminario de Nobles de Madrid, en AHN, Universidades, 667, exp. 125. 


\section{Oficios más condecorados de la república servidos por la familia Espinosa}

Entre los oficios más condecorados de la república que los Espinosa ejercen en la capital orensana, destaca - por la importancia que tuvo en su afianzamiento como familia de poder - la regiduría y la depositaría general que estos sirvieron de manera continuada en su concejo a partir de 1609 en adelante, justo hasta la generación precedente a la del citado Benito Mosquera Pimentel Espinosa y Berbetoros (López Díaz, 2013b, pp. 191-193). Se trata de uno de los 32 oficios acrecentados de que fue objeto esta institución entre 1591 y 1666, previo incluso al año en que se produce la reversión de este núcleo urbano al realengo en 1628, fecha a partir de la cual el proceso de acrecentamiento municipal experimenta aquí su máximo desarrollo, y que debemos poner en relación con las urgencias hacendísticas de la monarquía (López Díaz, 2011a, pp. 170-175). Tal como hemos comprobado en el apartado anterior, el licenciado Francisco de Espinosa sucede el 23 de octubre de 1609 a su suegro Rodrigo Arias de Malburgo en la posesión y ejercicio del oficio de depositario general de la ciudad con voz y voto de regidor «por dos vidas», que aquel había adquirido del monarca el 19 de julio de 1599 y cuya toma de posesión fuera objeto de controversia en el consistorio orensano por parte de los munícipes, en sesión celebrada el 27 de abril de $1600^{41}$. Rodrigo Arias de Malburgo, quien consta en alguna acta sacramental como platero, era padre de la segunda mujer del licenciado Espinosa, con la que este no había logrado tener descendencia directa, y de al menos otros cinco vástagos más — tres varones y otras dos mujeres - que había tenido con su esposa Inés González ${ }^{42}$.

Desconocemos los motivos exactos que le movieron a elegir a dicho su yerno como segundo usufructuario del oficio concejil que había comprado una década atrás, aunque es bastante probable que hubiese influido en su decisión la buena posición de los Espinosa en la sociedad auriense, entonces integrados en el sector de los hombres de leyes, sin perder de vista que la depositaría general se relaciona directamente con el ejercicio de la justicia; como también el hecho de que aquel había sido seleccionado como primer beneficiario del mayorazgo fundado por su padre en 1603; e incluso no deberíamos descartar que algunos de los sujetos que portaban entonces el mismo apellido de la familia de poder que aquí nos ocupa, eran igualmente plateros y seguían manteniendo cierta relación con esta. Sea como fuere, una vez accedió al oficio, el

\footnotetext{
$41 \quad$ AHPOu, Serie Municipal (en adelante SM), Ayuntamiento de Ourense (en adelante AOu), Libros de acuerdos (en adelante LA), c. 24135, consistorio celebrado en (en adelante co.) 27/4/1600, ff. 158r159 v; c. 24136 , co. $23 / 10 / 1609$, f. 302 r/v; y c. $24140 / 02$, co. 11/4/1652, f. 18 r/v para más detalle sobre las fechas de los correspondientes títulos del oficio.

42 AHDOu, FP, LAS, lib. 30.9.1, ff. 82r, 99v, 115v, 141r, 184r y 245v.
} 
licenciado - y abogado - Francisco de Espinosa logró que el monarca, primero, le concediese el 8 de febrero de 1615 la ampliación de «la [...] merced de seguir él y los que adelante subçedieren en el dicho offiçio le pudiesen pasar con solo una renunçiazión en vida o en muerte», y luego, el 30 de julio de 1624, que «se le perpetúa por juro de heredad»; sentando con ello las bases para su anexion al mayorazgo que se consuma cuando este decide incluirlo como parte de la agregación vincular que realiza en $1635^{43}$. Desde entonces, este oficio municipal pasa a formar parte del patrimonio amayorazgado de la familia, cuyos miembros van a disponer de él como si de una propiedad más amortizada se tratase ${ }^{44}$.

En la siguiente generación, sirvieron dicho oficio tres de sus hijos y su único yerno. Fue el mayor de sus vástagos, Antonio — quien habría de seguir posteriormente la carrera eclesiástica-, el primero en recibir la correspondiente real cédula y título, el 16 de julio de 1638, que le habilitaba para tomar posesión del mismo en el concejo auriense, si bien se desconoce la fecha en que esta se produjo ${ }^{45}$. Tres años después hace dejación del mismo, el 24 de enero de 1641, a favor de su madre y sus dos hermanas Francisca y Teresa, la segunda de las cuales se hallaba casada - recordemos - con el capitán Juan Feijóo de Nóvoa, señor de Bóveda de Limia ${ }^{46}$. Otros tres años más tarde, es el nuevo jefe de casa, su hermano Nuño, quien presenta en el concejo, el 11 de enero de 1644, el título expedido por el monarca para que se le dé la posesión de la depositaría general con voz y voto en el ayuntamiento, «en el ynterin no se açe y feneçe la partija [...] de los bienes y acienda que fincó de dicho su padre», dándosela en el consistorio celebrado ese día ${ }^{47}$. A finales del año siguiente, el 12 de diciembre de 1645 , hace lo propio su cuñado Juan, recibiendo del concejo la posesión en el oficio, que este va a servir hasta el momento de su defunción pasados cinco años, intervalo durante el cual sigue sin llevarse a cabo la citada partija ${ }^{48}$. Habrá que aguardar todavía hasta comienzos de 1650, más de doce años después del fallecimiento del licenciado Francisco de Espinosa, para que se produzca finalmente el reparto de los bienes que de él habían quedado; operación a la que solo concurren su viuda, sus dos hijas — ya

\footnotetext{
43 AHPOu, SM, AOu, LA, c. 24140/02, co. 11/4/1652, f. 18 r/v; y AHPOu, PN, Ou, c. 3571/02 (1635), ff. $1 \mathrm{r}-3 \mathrm{v}$.

44 También los Boán anexionan al mayorazgo familiar el oficio de regidor perpetuo de la ciudad de Ourense que adquieren a través de un testaferro o intermediario en 1640 (Rionegro Fariña, 2013, pp. 122-123; y López Díaz, 2013b, pp. 194-195).

45 Téngase en cuenta que Antonio, en tanto en cuanto hijo mayor del licenciado Espinosa, fue elegido por aquel como primer usufructuario del nuevo vínculo de 1635, en el que se incluye el mencionado oficio municipal. AHPOu, PN, Ou, c. 3571/02 (1635), ff. 1r-3v; y AHN, OOMM, Santiago, exps. 2765 , f. 47 r/v, y 2766 , f. 61 r.

46 AHPOu, PN, Ou, c. 3573/02 (1641), f. 34 r/v.

47 AHPOu, SM, AOu, LA, c. 24139/02, co. 11/1/1644, ff. 301v-303r.

48 AHPOu, SM, AOu, LA, c. 24139/03, co. 12/12/1645, ff. 58r-59r.
} 
habiendo enviudado la segunda de ambas - y Nuño de Espinosa Sotelo, a quien se le adjudica «el oficio de regidor y depositario general de la çiudad que fincó del dicho su padre» y que aquel había vinculado en $1635^{49}$. Cinco meses después nombra a su apoderado para que se presente en la Cámara y pida se le despache el título de dicho oficio, tardando todavía dos años más en que el consistorio orensano le dé la posesión el 11 de abril de $1652^{50}$.

El tercero de los hermanos al que el monarca hizo merced de expedirle el correspondiente título del oficio de regidor y depositario general de la ciudad, fue al capitán García de Espinosa Sotelo, el 27 de marzo de 1667, después de que Nuño lo hubiese renunciado, aunque al igual que había sucedido con Antonio desconocemos la fecha en que se efectuó la toma de posesión ${ }^{51}$. En otro orden de cosas, y ahondando en los méritos acumulados por la familia, es en esos años cuando García accede a la tenencia de la regiduría que posee el conde de Monterrei en el ayuntamiento orensano, exactamente el 25 de noviembre de $1669^{52}$; lo cual nos permite inferir que los Espinosa debían de tener contactos y/o relaciones con algunos sujetos próximos al entramado administrativo de esta casa condal, cuyo verdadero alcance se nos escapa y que seguramente fuesen más allá del simple hecho de que su madre era oriunda del núcleo poblacional que actúa como capital de su estado nobiliario gallego: la villa de Monterrei (González de Ulloa, 1777, p. 45) 5 .

El siguiente traspaso en la titularidad de este oficio municipal propiedad de la familia se efectúa a finales de la centuria, exactamente en 1699. No obstante, siete años antes de que aconteciese la muerte de Nuño, su hijo Juan Nicolás de Espinosa Feijóo — quien habría de sucederle en la jefatura familiar - estuvo en condiciones de acceder a otra plaza en el concejo orensano a consecuencia de su primer matrimonio con Felipa del Río Caraza. El abuelo de esta, el burgalés Juan del Río, había adquirido en 1638 una de las dos regidurías acrecentadas en esta institución con la preeminencia adscrita de la alcaldía mayor de ronda, que hereda su hijo Francisco del Río — padre de Felipa - en 1640. La familia de su mujer tenía además la propiedad de la escribanía de millones de la ciudad, que la Corona había puesto en venta en 1635 (López Díaz, 2011a, pp. 173, 193-196). En 1689, se le presentó la ocasión de acceder por esta vía al consistorio, aunque los capitulares habrían de sostener años más tarde que no había

AHPOu, PN, Ou, c. 3573/06 (1650), s. f. La partija se efectúa en 13/2/1650.

AHPOu, SM, AOu, LA, c. 24139/02, co. 11/4/1652, ff. 17r-20r; y AHPOu, PN, Ou, c. 3573/06 (1650), s. f. Este poder es otorgado por Nuño de Espinosa Sotelo en 11/7/1650.

AHPOu, SM, AOu, LA, c. 24146/04, co. 25/5/1699, ff. 24v-25r.

AHPOu, SM, AOu, LA, c. 24142/04, co. 25/11/1669, f. 88r/v.

Un caso análogo y coincidente en el tiempo es el de Antonio de Vivero Suárez de Navia y Villamil, quien fue teniente de regidor del x conde de Lemos en el regimiento orensano entre 1677 y 1684 (Presedo Garazo, 2016, pp. 243-244). 
sacado entonces el preceptivo título expedido por el monarca, quizá porque este no presentó en tiempo y forma el que le había sido despachado el 28 de mayo de $1691^{54}$.

Tres factores contribuyeron a tensar la situación justo en los años siguientes: $1^{\circ}$ ) la causa judicial que se inicia en 1691 entre su padre y la corporación municipal por el empleo de la depositaría general, que todavía se habrá prolongar hasta mediados del siglo XVIII (López Díaz, 2013b, p. 192); $2^{\circ}$ ) la deuda de 41.000 reales que aquel le reclamaba a esta institución por los gastos y salarios en el seguimiento que había realizado del pleito mantenido por las ciudades de Ourense y Santiago de Compostela contra las otras cinco capitales de provincia gallegas por el tanteo de las rentas reales en Galicia ${ }^{55}$; y $3^{\circ}$ ) el memorial que presenta en 1692 el propio Juan Nicolás, junto con otros dos regidores orensanos, ante el Consejo de Castilla denunciando los desórdenes en el normal funcionamiento del ayuntamiento auriense (López Díaz, 2011a, pp. 207-208; ID., 2013a, pp. 111-115; ID., 2013b, pp. 173-176) ${ }^{56}$. Esta situación habría de experimentar todavía un nuevo giro a mediados de 1695. En junio de ese año, Juan Nicolás se querella en la Real Audiencia contra el corregidor orensano, por el «auto de prisión y envargo de vienes» dado en su contra por los 3.530 reales que había pedido prestados «para ynbiar a la villa de Madrid para los gasttos y asistencias de pleittos que dicha ciudad tiene pendientes en ella», y una multa de diez ducados que también le había impuesto por haber participado en una votación ${ }^{57}$. Cinco meses después, el 5 de noviembre de 1695, renuncia el oficio de regidor a favor de su cuñado Jacinto Bernabé de Araúxo y Sandoval, «con condizión de que muerto dicho don Jacintto Bernavé buelba [...] a la persona a quien tocare por erencia y subçesión»; y, apenas doce días después, envía un escrito al concejo informando que no puede asistir al consistorio para el que se le ha convocado y que se celebra el día 18 de noviembre de $1695^{58}$.

AHPOu, SM, AOu, LA, c. 24146/01, co. 29/3/1696, f. 30v; y c. 24147/04, co. 27/2/1706, f. 44r.

55 Este pleito fue seguido ante el Consejo de Hacienda y el Consejo Real. La solicitud presentada en 17/3/1692 ante la Real Audiencia de Galicia por el procurador de Nuño de Espinosa Sotelo, pidiendo «se sirba mandar que dicha ciudad de Santiago le dé satisfación a mi parte de las dos que le tocan pagar de dichas cantidades», en ARG, RA, CP, leg. 17.749/22, s. f. Para la cantidad, que según Nuño le debía el concejo orensano, AHPOu, PN, Ou, c. 3422/01 (1696), ff. 212v-213r. Más información al respecto en AJRG, vol. IX (1677-1679), pp. 237-239, 241-250 y 549-550.

$56 \quad$ El nombramiento de apoderado hecho por el concejo orensano en 1696 para que este se presente ante el Consejo de Castilla a contradecir el real despacho que se había expedido a petición de Juan Nicolás de Espinosa Feijóo, Juan Antonio de Lemos y Juan Antonio de Soto Vilamarín, en AHPOu, PN, Ou, c. 3422/01 (1696), f. 28 r/v.

57 ARG, RA, CP, leg. 10.158/53, s. f. La querella es presentada el día 25/6/1695.

58 AHPOu, SM, AOu, LA, c. 24145/08, co. 18/11/1695, f. 69r; y c. 24146/01, co. 29/3/1696, f. 32r. Creemos que no se debe descartar para comprender el contexto en el que se produce la renuncia de dicha regiduría que hace Juan Nicolás de Espinosa Feijóo a favor de su cuñado Jacinto Bernabé, la solución al conflicto interfamiliar por la granja de A Barxa comentado páginas atrás. Vid. nota 19. 
A finales de marzo de 1696, el regimiento no le permite tomar posesión de la escribanía de millones; si bien tres meses más tarde, su apoderado presenta en el consistorio que tiene lugar el 12 de julio de 1696 la real cédula por la que se manda que se le dé «la possesión del oficio de alcalde mayor y rexidor que usava y exercía y [además] diese la possesión de la scrivanía de millones desta çiudad, para que le usasse por thenientes», todo lo cual es acatado y cumplido por la institución ${ }^{59}$. Tenemos constancia de que al menos nombró a un teniente para el ejercicio de dicha escribanía de millones a comienzos de mayo del año siguiente; $y$, asimismo, de que a mediados de mayo de 1701 se opuso al capitán Antonio Cisneros, juez nombrado por el gobernador y capitán general del reino de Galicia, el príncipe Barbanzón, con el cometido de cobrar la cantidad adeudada de sisas y millones por la ciudad de Ourense, alegando que a su mujer le pertenece «el oficio de escrivanía de millones desta dicha ciudad y provincia» por regalía, y que aquel no podría llevar a cabo su cometido «sino con el dicho mi teniente» y no con el escribano que había traído consigo ${ }^{60}$.

Al poco de morir Felipa del Río Caraza a comienzos de 1703, y aún habiendo fundado y dotado en memoria suya Juan Nicolás una obra pía en la Catedral de Ourense, situando la dotación en un juro sobre el servicio de millones del reino de Galicia ${ }^{61}$, este se vio envuelto en un nuevo litigio que habría de llegar hasta el Consejo Real contra Jacinto de Laiseca Alvarado, vecino de la villa de Chinchón y legítimo sucesor del mayorazgo que habían fundado Juan del Río y su mujer Felipa Caraza Agustina. El fallo que emitió esta instancia el 28 de julio de 1705 dio la razón al segundo, quien, tras obtener la preceptiva real cédula, tomó posesión el 27 de febrero de 1706 - a través de su apoderado - de la alcaldía mayor de ronda y regiduría que hasta el momento había servido el I marqués de Bóveda de Limia ${ }^{62}$.

De todos modos, este acontecimiento no representó en absoluto la salida de los Espinosa del concejo, habida cuenta de que seguían poseyendo la regiduría y depositaría general incluidas en la agregación vincular de 1635. Lo que aconteció es que, en vez de ocupar dos asientos, continuaron disponiendo tan solo del primero de ellos, que - como hemos visto líneas arriba — sí habían logrado anexionar al patrimonio

AHPOu, SM, AOu, LA, c. 24146/01, co. 29/3/1696, ff. 29v-33r, у co. 12/7/1696, ff. 48v-49r. AHPOu, PN, Ou, c. $3422 / 02$ (1697), f. 102r; y c. 81/01 (1697-1706), f. 31 r/v, respectivamente. AHPOu, PN, Ou, c. $3177 / 04$ (1703), ff. 140r-142v.

Jacinto de Laiseca y Alvarado nombra a su hijo Juan como su teniente en 1710. Este segundo toma posesión del oficio en 1717, y su hijo Luís de Laiseca y Alvarado lo hará en 1736. AHPOu, SM, AOu, LA, c. $24147 / 04$, co. $27 / 2 / 1706$, ff. 41 r- 43 v; c. 24148 , co. 6/6/1710, f. 75 r; c. $24149 / 06$, co. 8/1/1717, f. 1v; y c. 24152/06, co. 22/9/1736, ff. 138v-139r. Juan Nicolás de Espinosa Feijóo siguió manteniendo contacto con Juan de Laiseca y Alvarado, asistiendo como testigo al poder que este da a su mujer Melchora María Carrasco Ladrón de Guevara en 1724, para que pueda otorgar por él su testamento. AHPOu, PN, Ou, c. 3236/04 (1720-1727), f. 152 r/v. 
familiar ${ }^{63}$. Este oficio, a la muerte de Nuño de Espinosa Sotelo acaecida a finales de 1696, pasó - junto con el resto del patrimonio amayorazgado - a su hijo Juan Nicolás, a quien también había beneficiado su padre con un nuevo vínculo ${ }^{64}$. En 1699, año en que además le sucede en las diligencias que aquel había iniciado en la Real Audiencia en 1692 para que se le abonasen los salarios por el seguimiento que había hecho del pleito por el tanteo de las rentas reales ${ }^{65}$, renuncia dicho oficio el 18 de enero de 1699 a favor de su cuñado, el mencionado Jacinto Bernabé de Araúxo y Sandoval, quien es admitido por el concejo el 25 de mayo de 1699 tras presentar el preceptivo título real ${ }^{66}$. Escasamente un mes antes de que Juan Nicolás se oponga al delegado del gobernador y capitán general del reino de Galicia, por no haber tenido en cuenta que le correspondía la escribanía de millones de la ciudad, Jacinto Bernabé da su poder a dos sujetos - a finales de abril de 1701 — para que en su nombre «puedan aver y cobrar, recibir y recaudar todas y cualesquiera cantidades» que le corresponden, por su condición de depositario general, «de las condenaciones y penas de cámara que resultan para Su Magestad [...] y gastos de justizia que en la vesita y residenzia [...] se está tomando en dicha ciudad a los escribanos, notarios legos de ella y partidos de su provinzia», por parte del licenciado Antonio Salazar y Alvarado, comisionado para ello por el gobernador y oidores de la Real Audiencia gallega ${ }^{67}$.

Como ya hemos comentado, 1701 resulta un año clave para los Espinosa, puesto que es cuando el primer monarca de la dinastía Borbón, recién iniciado su reinado e inmerso en el conflicto sucesorio, le expide el título de marqués de Bóveda de Limia, previa concesión del vizcondado de Lamas (Felices de la Fuente, 2012, pp. 124-125). Con ello, pasan a formar parte del reducido grupo de capitulares aurienses que, ocupando un asiento en el concejo, han sido distinguidos con un título nobiliario (López Díaz, 1991, p. 57; Hernández Benítez, 1995, pp. 84-85; Aranda Pérez, 1999, pp. 286-289). En todo caso, no debemos perder de vista que cuatro años después — como también hemos visto - Juan Nicolás de Espinosa Feijóo cesa en la alcaldía mayor de ronda y

63 Sin contar, claro está, la tenencia de la regiduría del conde de Monterrei que servía desde 1669 García de Espinosa Sotelo.

64 Aunque no se conservan las actas de defunción de santa Eufemia la Real-Norte para 1696, todo apunta a que Nuño debió de haber muerto poco después de otorgar su testamento a mediados de septiembre de dicho año. Por su hijo Juan Nicolás de Espinosa Feijóo sabemos que fue enterrado en la misma capilla catedralicia en que había sido enterrado su abuelo paterno el licenciado Francisco de Espinosa (AHPOu, PN, Ou, c. 3236/04 (1720-1727), f. 5v); y no consta en el registro de difuntos de santa Eufemia la Real-Centro entre 1696 y 1698, ni tampoco en el de santa Eufemia la Real-Norte en 1697 y 1698.

65 ARG, RA, CP, leg. 17.749/22, s. f. Juan Nicolás de Espinosa Feijóo sigue las diligencias de esta causa hasta 1703 .

66 AHPOu, SM, AOu, LA, c. 24146/04, co. 25/5/1699, ff. 24r-25v.

67 AHPOu, PN, Ou, c. 3235/03 (1701-1704), ff. 16r-17r de 1701. 
regiduría y en la escribanía de millones de la ciudad. Será preciso aguardar hasta 1713, para que acceda por vez primera a la regiduría y depositaría general propiedad de su familia, luego de que su cuñado Jacinto Bernabé se la haya retrocedido, coincidiendo con el año en que el Consejo de Castilla resuelve finalmente la situación de desorden generada por las tenencias de regiduría que el propio Juan Nicolás había puesto en su conocimiento en $1692^{68}$.

Dos décadas más tarde, este renuncia el oficio el 25 de febrero de 1731 a favor de su hijo de nombre homónimo, quien toma posesión del mismo en el consistorio celebrado el día 9 de agosto de ese año. Cuatro años después de la defunción de Juan Nicolás de Espinosa Feijóo y Berbetoros, el concejo le da la posesión del oficio familiar el 16 de enero de 1748 al único cuñado de este último y único yerno del I marqués de Bóveda de Limia, José Antonio Pimentel Mosquera ${ }^{69}$. Será el hijo de José Antonio, Benito Mosquera Pimentel Espinosa y Berbetoros — quien, recordemos, había ingresado en 1754 en el elitista Real Seminario de Nobles de Madrid- el último miembro de la familia que tome posesión de la regiduría y depositaría general el 18 de agosto de 1777 , aunque no lo ejercerá ${ }^{70}$. En menos de un siglo, las palabras empleadas por su bisabuelo materno Nuño de Espinosa Sotelo en 1696 habían comenzado a perder parte de su significado original, a consecuencia de los cambios que se aprecian en el concejo orensano conforme se abre camino la década de los años 1720 (López Díaz, 2013a, pp. 115-116; ID., 2013b, pp. 176 y 193).

No podemos finalizar este apartado sin hacer una brevísima mención a otros oficios cuyo ejercicio desempeñaron los Espinosa en el transcurso del siglo XVII y que les reportaron igualmente honra. Nos referimos, en primer lugar, al que debemos considerar de mayor rango en la ciudad de Ourense una vez se produce su incorporación al realengo, esto es, el cargo de corregidor, que sirvió el licenciado Francisco de Espinosa en varias ocasiones en calidad de teniente y como interino, coincidiendo con la etapa en que se firma la concordia de febrero de 1628 por la cual se reconoce definitivamente dicha incorporación (Gallego Domínguez, 2005, p. 58; López Díaz, 2011a, p. 192). En segundo lugar, su condición de munícipes propició su elección por parte del concejo como regidores-procuradores o diputados encargados de representar a esta ciudad en las Juntas del Reino, en diferentes ocasiones a lo largo de la centuria. Concretamente, el licenciado Espinosa asistió como diputado orensano a las reuniones de esta institución que se celebraron en julio de 1629 y febrero y mayo de 1630;

68 AHPOu, SM, AOu, LA, c. 24152/01, co. 9/8/1731, f. 38 r.

69 Cuando se llevan a cabo en la ciudad de Ourense las operaciones relacionadas con la elaboración del catastro de Ensenada, es este quien figura como regidor y depositario general. AHPOu, CE, lib. 2564, Interrogatorio de la ciudad de Ourense, ff. 23r-25r.

70 AHPOu, SM, AOu, LA, c. 24152/01, co. 9/8/1731, ff. 34r-41r; c. 24155/03, co. 16/1/1748, ff. 2v-6r; c. $24158 / 03$, c. $14 / 7 / 1770$, ff. $31 v-32$ r; c. $24159 / 01$, co. $18 / 8 / 1777$, ff. $19 v-20 v$. 
su hijo Nuño de Espinosa Sotelo lo hizo en la reunión de abril de 1664; su otro hijo García de Espinosa Sotelo, a la que se habría de prolongar desde septiembre de 1677 hasta septiembre de 1678, y a la de enero de 1679; y su nieto Juan Nicolás de Espinosa Feijóo a la que tuvo lugar entre noviembre de 1692 y mayo de $1693^{71}$.

\section{Otras dos importantes vías de promoción: Iglesia y ejército}

El lustre de la familia también se vio reforzado por los méritos alcanzados por aquellos deudos que siguieron la carrera eclesiástica o bien sirvieron al monarca mediante el oficio de las armas. En ambos casos, la aportación fue considerable, pero es la segunda vía la que realmente acabó representando un trampolín de ascenso — en cuanto a nuevos méritos aportados se refiere - en las dos primeras décadas del siglo XVIII.

Tal como era costumbre entre las elites locales, algunos miembros de la familia llegaron a formar parte del cabildo de la Iglesia Catedral de Ourense (López Díaz, 1991, pp. 109-110; Hernández Benítez, 1995, pp. 192-193; Iglesias Ortega, 1996, pp. 438-440; Irigoyen López, 2000, pp. 188-190). En la etapa inicial de la edad moderna, un hermano de García de Espinosa, Juan, estaba integrado en esta institución catedralicia ocupando una canonjía, y un pariente suyo, procedente de otra rama familiar - Antonio Sotelo y Nóvoa - se había hecho con el deanato (Yzquierdo Perrín, 1995, pp. 124-125). En 1639, un año después de haber recibido la real cédula y título que le habilitaba para tomar la posesión en el concejo de la regiduría y la depositaría general, Antonio de Espinosa Sotelo iniciaba su carrera eclesiástica que le habría de llevar a ocupar otra canonjía y el arcedianato de Ourense ${ }^{72}$. Y en la siguiente generación, ya a caballo entre los siglos XVII y XVIII, accedieron a sendas canonjías dos hermanos de Juan Nicolás de Espinosa Feijóo: primero Tomás Manuel, quien además se hace cargo de la tesorería de la mesa capitular, y más tarde — previo paso por el curato de santa María de Bóveda - García. Como era habitual en estas familias vinculadas al poder local, las legítimas de ambos hermanos revertieron al patrimonio familiar en 1720 y 1701, respectivamente, con la intención de que «se mantenga el lustre de su Casa y subzesores en ella», tal como indica el canónigo y tesorero Tomás Manuel en la cesión que realiza a favor de Juan Nicolás ${ }^{73}$.

$71 \quad$ AJRG, vol. I (1599-1629), pp. 410-429 y 576; vol. II (1630-1636), pp. 77-103 y 523-524; vol. VII (1655-1665), pp. 326-340, 520 y 718-732; vol. IX (1677-1679), pp. 87-180, 270-272, 314-315, 475, $479-501,532-535,543,551-552,593-608$ y 615-617; vol. XI (1690-1697), pp. 166-269, 472-477, 523-524, 529, 552-560 у 563-578.

72 Ese año, su madre Francisca de Barros Sotelo — ya viuda del licenciado Francisco de Espinosalo apodera para que pueda pagar en su nombre el coste de las bulas para acceder a dicha canonjía y arcedianato. AHPOu, PN, Ou, c. 3572/02 (1639), ff. 286v-287v.

73 AHPOu, PN, Ou, c. 81/01 (1697-1700), ff. 20 r-21v y 24 r/v; y c. 3236/04 (1720-1727), ff. 2 r/v y 11r-12r. Para un comportamiento parejo, también en el tránsito del siglo XVII al XVIII, en la familia 
En la medida en que el cabildo catedralicio fue una de las instituciones más poderosas y prestigiosas que tuvieron su sede en la ciudad durante los siglos modernos, los parientes integrados en él aportaban igualmente prestigio a la familia de la cual procedían. A mayores, estos eclesiásticos estaban en condiciones de establecer aquí nuevos contactos con otros miembros del alto clero secular auriense que, al igual que ellos, podían ser originarios de otras familias de poder. Así que no es de extrañar que algunas de las disputas surgidas por motivos diversos entre diferentes familias o facciones, dentro o fuera del concejo, pudiesen llegar a alcanzar cierto eco en el cabildo catedralicio; o viceversa (Irles Vicente, 1996, pp. 237 ss.). Es posible que nos hallemos ante una prueba de ello en el enfrentamiento que mantuvo Tomás Manuel con el deán y resto de integrantes del cabildo, del cual él formaba parte, por el impedimento que estos le pusieron para continuar disfrutando de un privilegio asociado a la tesorería capitular: emplear la sacristía para vestirse la sobrepelliz y la capa con que debía asistir a los actos litúrgicos celebrados por el cabildo en el coro de la basílica. Esto obligó al susodicho a querellarse contra ellos en la Real Audiencia en 1693, curiosamente al año siguiente de que su hermano se hubiese quejado ante el Consejo de Castilla de los desórdenes que se apreciaban entonces en el funcionamiento del consistorio orensano ${ }^{74}$.

Mayor relevancia tuvieron los méritos logrados por los parientes que optaron por la carrera militar (Saavedra Vázquez, 2017, pp. 530-536). Pese a que, como hemos visto en páginas precedentes, sus orígenes se relacionan con los hombres de leyes, los Espinosa acumularon honores a través de esta vía en las tres generaciones que se suceden entre Nuño de Espinosa Sotelo y sus nietos, siguiendo la estela de otras familias homólogas que, como fue el caso de los Salgado Gundín o los Lemos, participaron primero en las campañas militares en que se vieron envueltos los Austrias en el siglo XVII, y luego, en la primera década del XVIII, en la Guerra de Sucesión española apoyando al bando borbónico (Gómez Buxán, 2007, pp. 162, 165-166; Bangueses Cobelas, 2012, pp. 102-106, 118; Andújar Castillo, 2004, pp. 49-54; López Díaz, 2009; García Heras, 2011; Saavedra Vázquez, 2013, pp. 234-243; ID., 2017, pp. 527 ss.). Así, en los años centrales del Seiscientos, coincidiendo con la guerra de restauración portuguesa, su hermano García de Espinosa Sotelo llegó a alcanzar la graduación de capitán en una de las compañías del tercio de infantería que estuvo destacado en Monterrei al mando de Antonio Taboada Ribadeneira; cuya misión consistió en vigilar un tramo de la frontera galaico-portuguesa que se extendía a lo largo de unos sesenta kilómetros, y que en 1645 protagonizó una incursión en territorio enemigo contra la

leonesa Escobar y Osorio que detenta una regiduría en el concejo de la ciudad de León, vid. Bartolomé Bartolomé, 2019, pp. 386-387. 
Torre de Ervededo y las fortificaciones levantadas en los lugares de Bustelo y Souteliño, cercanos a la plaza de Chaves (Olga Gallego, 2005, p. 62; Díaz-Castroverde Lodeiro, 2012, pp. 248-251; Saavedra Vázquez, 2007; pp. 145-147). También Nuño sirvió en la infantería del rey, si bien en un destino aún más lejano: los Países Bajos, y — según las fuentes consultadas - en una cronología anterior a los años setenta. Por su hijo Juan Nicolás sabemos que fue distinguido con «el empleo de sarxento mayor [...] en uno de los regimientos de ynfantería española de dichos estados de Flandes» ${ }^{75}$.

Tres de los vástagos de Nuño de Espinosa Sotelo optan de nuevo por la carrera militar en el último cuarto de siglo, siguiendo dos de ellos sus mismos pasos, puesto que van a servir en la infantería española destinada en los Países Bajos (Rodríguez Hernández, 2007; Saavedra Vázquez, 2009, pp. 462-468; ID., 2016, pp. 133-136, 142143; ID., 2017, pp. 530-531). Jacinto Antonio de Espinosa Feijóo ya llevaba allí trece años, habiendo comenzado de niño con once y alcanzado la graduación de capitán de dicho cuerpo con diecinueve, cuando las Juntas del Reino lo proponen en mayo de 1678 para sargento mayor del tercio que el Reino ofrece al monarca en esa ocasión; en abril de 1689, siendo capitán de caballos arcabuceros, es propuesto nuevamente por las juntas para la maestría de campo de uno de los dos tercios ofrecidos ese año; y en 1693, estas acuerdan escribir al monarca «suplicándole se sirva premiar los serbiçios de don Jaçinto Antonio de Espinosa» con «un terçio de infantería en los estados de Flandes» ${ }^{76}$. Cuando en 1694 se realizan los expedientes para que sus hermanos Juan Nicolás y Martín Carlos puedan acceder a sendos hábitos de la Orden de Santiago, a mediados de abril todavía vivía y consta como señor de la Casa de Bóveda, «solariega del apellido Feixóo» ${ }^{77}$. Pero dos años más tarde, a mediados de septiembre de 1696, cuando su padre redacta su testamento, ya había fallecido. Por entonces, también se hallaba sirviendo en una compañía de infantería en los Países Bajos su otro hermano José Bernardino, quien, coincidiendo con dicho destino, se casa con una mujer flamenca de cuya unión queda descendencia ${ }^{78}$.

Correspondió, en cambio, al tercero de los hermanos ser distinguido con mayores honores tras su paso por el ejército real. En 1694, cuando se convierte en cruzado de Santiago, consta que Martín Carlos había sido «muchos años capitán de caballos en Flandes, adonde le baldaron un brazo», y en 1696 portaba el rango castrense de co-

AHPOu, PN, Ou, c. 3422/01 (1696), f. 211v; y c. 3236/04 (1720-1727), f. 5r.

AJRG, vol. IX (1677-1679), pp. 139-144 y 552; vol. X (1681-1689), pp. 193-195; y vol. XI (16901697), pp. 179 y 197.

77 AHN, OOMM, Santiago, exp. 2765, ff. 69v-70r. Es muy probable que Jacinto Antonio sea el hermano referenciado en el expediente de Martín Carlos como «maestre de campo en Cataluña» en 1694. Ibid., exp. 2766, f. 49r.

78 AHPOu, PN, Ou, c. 3422/01 (1696), f. 214r. 
ronel $^{79}$; pero fue durante la etapa borbónica cuando habría de refrendar su trayectoria militar, convirtiéndose en el que quizá haya sido el Espinosa orensano mejor posicionado en las décadas iniciales del reinado de Felipe V. La documentación notarial que hemos revisado, relativa a su último año de vida y los dos siguientes ${ }^{80}$, apenas nos permite esbozar un esquema muy básico de esta, en la cual debemos mencionar, $1^{\circ}$ ) que alcanza las graduaciones de general de artillería, mariscal de campo y primer teniente de las reales guardias de Cors alabarderos; $2^{\circ}$ ) que fue nombrado gobernador de Jaca; $3^{\circ}$ ) que el monarca, «en atención a sus muchos y leales serviçios, le dio para sí y sus herederos legítimos en la villa de Elche del reino de Valencia diferente hazienda que estava gozando y llebando como suia propia por dicha merced». Ya hemos comentado páginas atrás los motivos por los cuales estos bienes acaban finalmente, en 1720, en poder de su hermano Juan Nicolás, por lo que no nos extenderemos ahora más sobre el asunto.

A diferencia de los cinco anteriores, la actividad castrense de Felipe Carlos de Espinosa, hijo de José Bernardino de Espinosa Feijóo — nieto, en consecuencia, de Nuño de Espinosa Sotelo- , debe ser puesta en relación exclusivamente con el ejército borbónico. En 1718, año en que se produce la muerte de su tío Martín Carlos, había alcanzado las graduaciones de capitán de caballos corazas y cadete reformado de las reales guardias de Cors, en la segunda de las cuales es muy probable que aquel hubiese podido llegar a tener cierta influencia. No sabemos el escenario ni el momento exactos en que devino en estado de invalidez en servicio del rey, pero justo en $1718 \mathrm{se}$ vio obligado a apoderar a su citado tío, residente en la corte, para reclamar «el sueldo que S. M. le tiene señalado y mandó situar por tal cadete ymbálido desde el tiempo que le es devido y dejó de pagar y está corrido asta aora y corriere a lo adelante», el cual se debía de cobrar, al menos en la parte que nos es conocida, sobre las rentas reales de las ciudades de Lugo y Coruña y sus respectivos partidos. En 1720 presenta otra solicitud, en esta ocasión al Intendente general de Galicia, para el cobro situado sobre las rentas coruñesas ${ }^{81}$.

Tras Felipe Carlos, parece que los Espinosa se vuelven más reacios a portar armas sin otro motivo que no sea la simple ostentación. En la línea sucesoria principal en la que recae el mayorazgo de 1603 y las posteriores agregaciones vinculares de 1635, 1696 y 1720, habrá que aguardar hasta Benito Mosquera Pimentel Espinosa y Berbetoros para encontrarnos a otro varón de la familia que haya alcanzado una gra-

\footnotetext{
79 Ibid. y AHN, OOMM, Santiago, exp. 2766, f. 49r

80 AHPOu, PN, Ou, c. 3236/01 (1710-1719), f. 16 r/v de 1718 y ff. 5r y 7r-8v de 1719; y c. 3236/04 (1720-1727), ff. 9r y 21r-22v.

81 AHPOu, PN, Ou, c. 3236/01 (1710-1719), ff. 16 r/v, 25 r/v y 68 r/v de 1718; y c. $3236 / 04$ (17201727), f. $33 \mathrm{r} / \mathrm{v}$.
} 
duación militar, la de capitán, pero a diferencia de sus antepasados, de un regimiento de milicias, en este caso de la ciudad de Betanzos (López Díaz, 2009, p. 119).

\section{Conclusiones}

Como familia de poder, los Espinosa orensanos adoptaron desde inicios de la edad moderna una serie de estrategias encaminadas a alcanzar y conservar un lugar destacado, y con peso propio, en las filas de la oligarquía de la ciudad de Ourense. Su vocación urbana, ya atestiguada desde la última centuria medieval, se vio reforzada cuando la línea familiar que arranca de García de Espinosa - en la segunda mitad del siglo XVI - logra acceder al regimiento auriense a inicios del XVII, en el contexto del acrecentamiento municipal que experimenta esta institución política local, culminando el ascenso familiar con Juan Nicolás de Espinosa Feijóo en los años finales del Seiscientos y las dos primeras décadas del Setecientos.

Entre ambos extremos, estos consolidan su ascenso en base a la adopción de una dinámica reproductiva que se sustenta en varios pilares. $1^{\circ}$ ) Su acercamiento, en una etapa inicial, al sector de los hombres de leyes de este núcleo urbano, al que corresponde la capitalidad provincial. $2^{\circ}$ ) Una política matrimonial restrictiva continuada, que tan sólo permite que acceda al matrimonio una parte reducida de la amplia prole que integra las sucesivas generaciones, con otras familias de los niveles elevados de la sociedad local, provincial e incluso interprovincial; donde, llegado el caso, se recurre a matrimonios a trueque y a las segundas y terceras nupcias. $3^{\circ}$ ) La consolidación de un modelo sucesorio claramente agnaticio que tiene su base en el mayorazgo de 1603, que, no obstante, facilita en la práctica que segundones como el mencionado Juan Nicolás de Espinosa Feijóo, o su padre Nuño de Espinosa Sotelo, puedan ocupar la jefatura de la casa. $4^{\circ}$ ) Un patrimonio amayorazgado que permanece unido a la línea familiar en la cual recaen los derechos sucesorios a dicho mayorazgo de 1603, al que se irán incorporando las posteriores agregaciones vinculares de 1635, 1696 y 1720. $5^{\circ}$ ) Un claro interés por incorporarse al concejo orensano como signo más representativo de su pertenencia a las elites locales aurienses. Y $6^{\circ}$ ) su presencia en el cabildo catedralicio orensano o en el ejército constituyen dos vías de reforzamiento del honor y el estatus de la familia.

Siendo todos ellos pilares imprescindibles para la consecución de su reproducción social exitosa en la larga duración, a finales del siglo XVII e inicios del XVIII, es evidente que esta había estado ligada en gran medida a los oficios que venían sirviendo en el concejo de dicha ciudad desde inicios de esta época histórica. El oficio acrecentado de la depositaría general con voz y voto de regidor, al que acceden en 1609 a través del mercado matrimonial y que incluyen en la agregación vincular de 1635 , 
es sin lugar a dudas el más relevante de ellos, siendo servido por siete miembros de la familia durante el siglo que transcurre entre la primera de ambas fechas y 1713. A este hemos de añadir otros dos oficios igualmente acrecentados que sirve Juan Nicolás de Espinosa Feijóo y su cuñado Jacinto Bernabé de Araúxo y Sandoval entre 1689 y 1706 a raíz de las primeras nupcias del primero de ellos: una regiduría con la preeminencia adscrita de la alcaldía mayor de ronda y la escribanía de millones. Y también la tenencia de la regiduría del conde de Monterrei que sirve García de Espinosa Sotelo en el último cuarto del siglo XVII. Más allá de los avatares relacionados con el traspaso de estos oficios, de la dificultosa relación que se observa entre esta familia de poder y el concejo orensano en los años finales del reinado de Carlos II, y de otros oficios que les aportaron honor y prestigio, creemos que queda probado que su trayectoria familiar se halla estrechamente condicionada por su presencia en el consistorio auriense.

Sobre esta base, debemos situar el cenit de los éxitos cosechados por la familia en los años iniciales del reinado del primer monarca de la nueva dinastía real que se hace con el trono español con la llegada del siglo XVIII. Es entonces cuando Felipe V le expide en 1701 el título nobiliario de marqués de Bóveda de Limia a Juan Nicolás de Espinosa Feijóo y recompensa a su hermano Martín Carlos por haberle servido diligentemente con el oficio de las armas y como gobernador de Jaca. Es más, dos generaciones posteriores a esta, los Espinosa incluso envían al Real Seminario de Nobles de Madrid al nieto del mencionado Juan Nicolás de Espinosa Feijóo que habrá de hacerse con la jefatura de la casa pasados los años centrales de la tercera centuria moderna. Paradójicamente, este cenit se alcanza en la antesala del nuevo escenario que se abre paso en el concejo orensano, que, desde mediados de la década de los años veinte, se va a caracterizar por el progresivo absentismo de los munícipes, al que tampoco será ajeno el mencionado nieto del I marqués de Bóveda de Limia.

\section{AGRADECIMIENTOS}

Trabajo realizado en el marco del proyecto de investigación El reino de Galicia en la monarquía de Felipe V: instituciones y dinámica política (Ref. HAR2017-83605-P), cofinanciado por el Ministerio de Ciencia e Innovación (Agencia Estatal de Investigación) y el Fondo Europeo de Desarrollo Regional (AEI/FEDER). 


\section{Bibliografía}

Acuña Rubio, Carlos (2002), «Títulos nobiliarios de los hijos de Galicia», Boletín de Estudios de Genealogía, Heráldica y Nobiliaria de Galicia, 1, pp. 37-50.

Aguilar Piñal, Francisco (1980), «Los reales seminarios de nobles en la política ilustrada española», Cuadernos Hispanoamericanos, 356, pp. 329-349.

Andújar Castillo, Francisco (2004), El sonido del dinero. Monarquía, ejército y venalidad en la España del siglo XVIII, Madrid, Marcial Pons.

Angulo Morales, Alberto (2007), De Cameros a Bilbao. Negocios, familia y nobleza en tiempos de crisis (1770-1834), Bilbao, Universidad del País Vasco.

Aranda PÉrez, Francisco J. (1999), Poder y poderes en la ciudad de Toledo. Gobierno, Sociedad y Oligarquías en la Edad Moderna, Cuenca, Universidad de Castilla-La Mancha.

Atienza Hernández, Ignacio (1997), «La construcción de lo real. Genealogía, casa, linaje y ciudad: una determinada relación de parentesco», en Casey, J. y Hernández Franco, J. (eds.), Familia, Parentesco, Linaje, Murcia, Universidad de Murcia, pp. 41-59.

Bangueses Cobelas, Mary Cruz (2012), O Pazo de Piñor, Ourense, Diputación Provincial de Ourense.

BARtolomé BARtolomé, Juan Manuel (2019), «De padres a hijos: revestimientos hereditarios, posiciones de linaje y decisiones individuales de una elite (17001850)», Tiempos Modernos, 38, pp. 380-404.

CASEy, James (2007), Family and community in early Modern Spain. The Citizens of Granada, 1570-1739, Cambridge, Cambridge University Press. <https://doi. org/10.1017/CBO9780511496707>

Chaparro SAInz, Álvaro (2012), «La génesis de una familia ilustrada vasca en el siglo XVIII», Cuadernos de Historia Moderna, 37, pp. 177-198. <https://doi. org/10.5209/rev_CHMO.2012.v37.39235>.

Clavero, Bartolomé (1974), Mayorazgo. Propiedad feudal en Castilla (1369-1836), Madrid, Siglo XXI.

DEDIEU, Jean-Pierre y WINDLER, Christian (1998), «La familia: ¿una clave para entender la historia política? El ejemplo de la España moderna», Studia historica. Historia Moderna, 18, pp. 201-233.

DíAz-CASTroverde Lodeiro, José Luís (2012), Morgados e xurisdicións na terra e condado de Taboada. Séculos XV-XVIII, Lugo, Asociación de Amigos do Mosteiro de Ferreira de Pallares. 
EIRAs Roel, Antonio (dir., 1995), Actas de las Juntas del Reino de Galicia (abreviado en el texto como AJRG), vol. I (1599-1629), Santiago de Compostela, Xunta de Galicia.

EIras Roel, Antonio (dir., 1997), Actas de las Juntas del Reino de Galicia, vol. II (1630-1636), Santiago de Compostela, Xunta de Galicia.

EIras Roel, Antonio (dir., 1999), Actas de las Juntas del Reino de Galicia, vol. VII (1655-1665), Santiago de Compostela, Xunta de Galicia.

EIRAs Roel, Antonio (dir., 2001), Actas de las Juntas del Reino de Galicia, vol. IX (1677-1679), Santiago de Compostela, Xunta de Galicia.

EIRAs Roel, Antonio (dir., 2002a), Actas de las Juntas del Reino de Galicia, vol. X (1681-1689), Santiago de Compostela, Xunta de Galicia.

EIras Roel, Antonio (dir., 2002b), Actas de las Juntas del Reino de Galicia, vol. XI (1690-1697), Santiago de Compostela, Xunta de Galicia.

Felices de la Fuente, María del Mar (2012), La nueva nobleza titulada de España y América en el siglo XVIII (1701-1746): entre el mérito y la venalidad, Almería, Universidad de Almería.

Ferro Couselo, Xesús (1967), A vida e a fala dos devanceiros. Escolma de documentos en galego dos séculos XIII ao XVI, 2 vols., Vigo, Galaxia.

Ferro Couselo, Xesús (1972), «Gente llana con ventura. Los Boanes», Boletín Auriense, II, pp. 7-73.

FORTEA PÉREZ, J. I. (2005), «Las ciudades, sus oligarquías y el gobierno del Reino», en Feros, A. y Gelabert, J. (dirs.), España en tiempos del Quijote, Madrid, Taurus, pp. 235-278.

Gallego Domínguez, Olga (2005), «A saga dunha estirpe ourensá: Os Espinosa de Ourense», Boletín Avriense, XXXV, pp. 51-84.

Gallego Domínguez, Olga y Fariña Busto, Francisco (2005), «Os Nóboa. Unha linaxe ourensá», Boletín Avriense, XXXV, pp. 155-176.

García Heras, Víctor Alberto (2001), «La Guerra de Sucesión como vía de ascenso social: don Gabriel Ortega Guerrero, II marqués de Valdeguerrero», Espacio, Tiempo y Forma. Serie IV, Historia Moderna, 24, pp. 127-141. <https://doi. org/10.5944/etfiv.24.2011.10839>

Gelabert González, Juan Eloy (1982), Santiago y la Tierra de Santiago de 1500 a 1640, Sada- Coruña, Ediciós do Castro.

Gómez Buxán, César (2007), «El condado de Borrajeiros. Notas para su historia» Hidalguía, 321, pp. 151-176.

González de UlloA, Pedro (1777), Descripción de los estados de la Casa de Monterrey en Galicia, Santiago de Compostela, Instituto de Estudios Gallegos Padre Sarmiento [edición a cargo de J. Ramón y Fernández Oxea, 1950]. 
Hernández Benítez, Mauro (1995), A la sombra de la Corona. Poder local y oligarquía urbana (Madrid, 1606-1808), Madrid, Siglo XXI.

HERnÁNDEZ FrANCO, Juan (1998), «El reencuentro entre historia social e historia política en torno a las familias de poder. Notas y seguimiento a través de la historiografía sobre la Castilla moderna», Studia Historica. Historia Moderna, 18, pp. 179-199.

Iglesias Ortega, Arturo (1996), «Análisis sociológico del cabildo compostelano a través de los expedientes de limpieza de sangre», Compostellanum, XLI-3/4, pp. 421-450.

Irigoyen LóPez, Antonio (2000), Entre el Cielo y la Tierra, entre la familia y la institución. El cabildo de la catedral de Murcia en el siglo XVII, Murcia, Universidad de Murcia.

IrLes ViCEnTE, María del Carmen (1996), Al servicio de los Borbones. Los regidores valencianos en el siglo XVIII, Valencia, Edicions Alfons el Magnànim.

JimÉNEZ MARTíNEZ DE LAGRÁN, Silvia (2009), «Estudio de la formación de una élite a través del rápido proceso de ascenso social de la familia Ruiz de Apodaca en el siglo XVIII», en Soria Mesa, E. y Molina Recio, R. (eds.), Las élites en la Época Moderna: la Monarquía Española, vol. 2. Familia y redes sociales, Córdoba, Universidad de Córdoba, pp. 295-304.

López Carreira, Anselmo (1993), De Ourense medieval. Rexistro de Xoán García, 1484, Ourense, Museo Arqueológico Provincial.

López Carreira, Anselmo (1995), Padróns de Ourense do século XV, Santiago de Compostela, Consello da Cultura Galega.

López Carreira, Anselmo (1998), A cidade de Ourense no século XV. Sociedade urbana na Galicia baixomedieval, Ourense, Deputación Provincial de Ourense.

López DíAZ, María (1991), Oficios municipales de Santiago a mediados del siglo XVIII, A Coruña, Estudios Mindonienses.

LÓPEz DíAz, María (2009), «Oligarquías urbanas y milicia: Apuntes sobre una relación beneficiosa a partir del caso de Ourense (siglo XVIII)», Cuadernos de Historia Moderna, 34, pp. 95-123.

LóPez DíAz, María (2011a), Jurisdicción e Instituciones locales de la Galicia meridional (XVI-XVIII), Vigo, Universidad de Vigo.

LóPEz DíAz, María (2011b), «Familia, relaciones sociales y estrategias familiares de las elites urbanas gallegas (XVI-XVIII)», en Santos, C. (coord.), Família, Espaço e Património, Porto, CITCEM, pp. 385-399.

LóPEz DíAz, María (2013a), «Élites locales y dinámicas de poder en la Galicia filipina: cambio dinástico y primeras tentativas reorganizadoras (1700-1722)», en López 
Díaz, M. (ed.), Élites y poder en las monarquías ibéricas. Del siglo XVII al primer liberalismo, Madrid, Biblioteca Nueva, pp. 99-127.

LóPez DíAz, María (2013b), «Regidores de Ourense y dinámicas duraderas: guía de titulares, oficios y familias (1650-1812)», Cuadernos Feijonianos de Historia Moderna, 4, pp. 165-220.

Peláez Ribero, María Dolores (2010), Os Méndez Montoto, 1507-1650: Unha familia do poder urbano ourensán, Trabajo de investigación para obtención del DEA, Inédito, Ourense, Universidade de Vigo.

PÉrez OrTiZ, Antonio L. (2002), «Trayectoria y reproducción social de una familia de comerciantes en la Murcia del siglo XVIII: el ejemplo de los Ferro», en Irigoyen López, A. y Pérez Ortiz, A. L. (eds.), Familia, transmisión y perpetuación (siglos XVI-XIX), Murcia Universidad de Murcia, pp. 265-277.

Postigo Castellanos, Elena (1988), Honor y privilegio en la Corona de Castilla. El Consejo de las Órdenes y los Caballeros de Hábito en el s. XVII, Soria, Junta de Castilla y León.

Precioso Izquierdo, Francisco (2017), Melchor Macanaz. La derrota de un «héroe», Madrid, Cátedra.

Presedo Garazo, Antonio (2013), «Hidalgos y casas hidalgas en la provincia de Ourense en la Edad Moderna», Cuadernos Feijonianos de Historia Moderna, 4, pp. 65-105.

Presedo Garazo, Antonio (2016), «Familia y poder en la Casa de Lagariños en tiempos de don Antonio de Vivero Suárez de Navia y Villamil (1628-1692)», Boletín Auriense, XLVI, pp. 227-253.

Presedo Garazo, Antonio (2019), «Entre la religiosidad barroca y el reforzamiento de estatus: El comportamiento religioso de los regidores de Ourense en 1680 1725», en Prada Rodríguez, J. y Rodríguez Teijeiro, D. (eds.), Indivisa manent. Estudos en homenaxe a Jesús de Juana, Vigo, Galaxia, pp. 105-134.

Rionegro FAriña, Isolina (2013), «Una familia de poder de la élite orensana: los Boán”, Cuadernos Feijonianos de Historia Moderna, 4, pp. 107-127.

Rodríguez Hernández, Antonio José (2007), «De Galicia a Flandes: reclutamiento y servicio de soldados gallegos en el ejército de Flandes (1648-1700)», Obradoiro de Historia Moderna, 16, pp. 213-251.

Rodríguez SÁnchez, Ángel (1992), «El poder y la familia. Formas de control y consanguinidad en la Extremadura de los tiempos modernos», en Chacón Jiménez, F. y Hernández Franco, J. (eds.), Poder, familia y consanguinidad en la España del Antiguo Régimen, Barcelona, Anthropos, pp. 15-34.

SAAVEDRA VÁzQuez, María del Carmen (2007), «Los protagonistas de la actividad militar en Galicia: Nobleza, ciudades y juntas del Reino (s.XVI-XVII)», en 
Jiménez Estella, A. y Andújar Castillo, F. (eds.), Los nervios de la guerra. Estudios sociales sobre el ejército de la monarquía hispánica (s. XVI-XVIII): nuevas perspectivas, Granada, Comares, pp. 121-148.

SAAVEdRa VÁzquez, María del Carmen (2009), «La actividad militar en Galicia durante el reinado de Carlos II: primeros datos y reflexiones», en López Díaz, M. (ed.), Historia y modernidad. Estudios en homenaje al profesor José M. Pérez García, Vigo, Universidade de Vigo, pp. 457-476.

SaAvedra VÁzquez, María del Carmen (2013), «La elite militar del Reino de Galicia durante la Guerra de Sucesión», en López Díaz, M. (ed.), Élites y poder en las monarquías ibéricas. Del siglo XVII al primer liberalismo, Madrid, Biblioteca Nueva, pp. 223-244.

SAAVedra VÁzQuez, María del Carmen (2016), «La defensa peninsular en tiempos de Carlos II: la experiencia gallega”, en Saavedra Vázquez, M. C. (ed.), La decadencia de la monarquía hispánica en el siglo XVII. Viejas imágenes y nuevas aportaciones, Madrid, Biblioteca Nueva, pp. 129-146.

SAAVEdra VÁzQuez, María del Carmen (2017), «El papel de las élites locales en la organización militar: Galicia, 1668-1715», en García Hernán, E. y Maffi, D. (eds.), Estudios sobre Guerra y Sociedad en la Monarquía Hispánica, Valencia, Albatros, pp. 519-538.

Soubeyroux, Jacques (1995), «El real seminario de nobles de Madrid y la formación de las élites en el siglo XVIII», Bulletin Hispanique, t. 97, 1, pp. 201-212. < https:// doi.org/10.3406/hispa.1995.4860>.

Yzquierdo Perrín, Ramón et al. (1995), La Catedral de Orense, León, Edilesa. 
